\title{
Ulcerative colitis: an update
}

\author{
Authors: Jonathan P Segal, ${ }^{A}$ Jean-Frédéric LeBlanc ${ }^{B}$ and Ailsa L Hart ${ }^{C}$
}

\begin{abstract}
Ulcerative colitis is a relapsing and remitting disease that is increasing in incidence and prevalence. Management aims to achieve rapid resolution of symptoms, mucosal healing and improvement in a patient's quality of life. 5-aminosalicylate acid medications remain the first-line treatment for mild to moderate disease. In the event of suboptimal response to these medications, escalation to immunosuppressive medications and biologics may be necessary. Importantly, despite best medical therapy, surgery may be required in a proportion of patients. The future will likely see an array of new therapeutic options for those with ulcerative colitis with the potential for a more personalised treatment approach.
\end{abstract}

\section{Introduction}

Ulcerative colitis $(U C)$ is a relapsing and remitting inflammatory bowel disease (IBD) characterised by mucosal inflammation which starts distally and can extend proximally to involve the whole colon. It has a reported incidence in the UK of $12.6 / 100,000$ person years (95\% confidence interval (CI) 11.4-13.9). Importantly, prevalence appears to be rising with the most recent data from the Lothian region highlighting a point prevalence of $432 / 100,000 .{ }^{2}$ UC has a bimodal age distribution with an incidence peak in the second or third decades and a second peak between 50 and 80 years. The aetiology involves interactions between the environment, immune system, gut microbiome and a genetic predisposition to disease. ${ }^{3}$ Ulcerative colitis presents with bloody diarrhoea, frequency, abdominal pain, fatigue and faecal incontinence.

The Montreal classification groups UC patients, based on their maximal disease extent, into E1 or proctitis (disease limited to the rectum); E2 or left-sided disease (distal to splenic flexure); and $\mathrm{E} 3$ or extensive colitis (disease extends proximal to splenic flexure). ${ }^{4}$ Patients with left-sided disease or extensive colitis are associated with higher risks of medication usage, colectomy and colorectal cancer. ${ }^{4}$ Besides disease extent, the main risk factors for colorectal dysplasia/cancer in UC include disease duration; active endoscopic or histological inflammation; presence of a stricture or post-inflammatory polyps; family history of colorectal cancer; and associated primary sclerosing cholangitis (a chronic inflammatory bile duct disorder which affects $3-7 \%$ of UC patients). ${ }^{5}$ Other extra-intestinal manifestations of UC include,

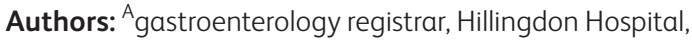
Uxbridge, UK; ${ }^{B}$ gastroenterology fellow, St Mark's Hospital, Harrow, UK; ' Consultant gastroenterologist, St Mark's Hospital, Harrow, UK and Imperial College London, London, UK in order of frequency, anaemia, arthropathy (axial or peripheral), cutaneous (erythema nodosum or pyoderma gangrenosum) and ocular manifestations (anterior uveitis or episcleritis), most of which mirror UC disease activity, except for ankylosing spondylitis and peripheral polyarthritis (Table 1 ). ${ }^{4}$

\section{Therapeutic goals and targets}

In 2015, the Selecting Therapeutic Targets in Inflammatory Bowel Disease (STRIDE) initiative made recommendations about

\section{Key points}

Ulcerative colitis is common, and incidence and prevalence are increasing.

Goals of treatment are to achieve prompt symptom amelioration and heal disease at the mucosal level, while restoring overall quality of life for the patient.

Patient engagement in their care and monitoring (with symptoms in addition to objective markers of inflammation) are key to optimal management so that therapies can be escalated as necessary.

5-ASA drugs represent the main therapies for mild to moderately active $U C$, and optimising adherence is important.

In UC patients with inadequate response to 5-ASA, immunosuppressive or biologic therapies are indicated, and choice is dependent on multiple factors, including patient choice.

Surgical options for ulcerative colitis are important to discuss with patients and include restorative options such as an ileoanal pouch or, rarely, an ileorectal anastomosis or a permanent ileostomy.

The future will see an array of new treatments with head-tohead trials allowing us to position treatments correctly.

KEYWORDS: ulcerative colitis, inflammatory bowel disease, biologics

DOI: $10.7861 /$ clinmed.2021-0080 
Table 1. Investigations for ulcerative colitis

\begin{tabular}{|c|c|c|c|}
\hline Investigation & Type of investigation & Common findings in UC & Notes \\
\hline Blood tests & $\begin{array}{l}\text { Full blood count } \\
\text { Urea and electrolytes } \\
\text { C-reactive protein } \\
\text { Vitamin D and bone profile } \\
\text { Haematinics } \\
\text { Liver biochemistry }\end{array}$ & $\begin{array}{l}\text { Anaemia, thrombocytosis, low } \\
\text { vitamin } D \text { and raised inflammatory } \\
\text { markers }\end{array}$ & $\begin{array}{l}\text { Consider pre-immunosuppressant/ } \\
\text { biologic screen in those } \\
\text { likely to need escalation to } \\
\text { immunosuppressant/biologic } \\
\text { therapy (including TPMT, viral } \\
\text { serology, quantiferon) } \\
\text { Primary sclerosing cholangitis } \\
\text { can be associated with UC and } \\
\text { can present with deranged liver } \\
\text { biochemistry }\end{array}$ \\
\hline Stool cultures & $\begin{array}{l}\text { Clostridioides difficile toxin assay } \\
\text { MC\&S }\end{array}$ & $\begin{array}{l}\text { Should be negative if UC, but } \\
\text { infections such as } C \text { difficile can } \\
\text { co-exist }\end{array}$ & $\begin{array}{l}\text { Take a thorough history, including } \\
\text { travel history to rule out other } \\
\text { causes } \\
\text { Recent antibiotic use may be } \\
\text { associated with C difficile }\end{array}$ \\
\hline Faecal calprotectin & $\begin{array}{l}\text { Indicates migration of neutrophils } \\
\text { to the lumen via the intestinal } \\
\text { mucosa }\end{array}$ & $\begin{array}{l}\text { A level of } 50-100 \mu \mathrm{g} / \mathrm{g} \text { has a } \\
\text { high negative predictive value of } \\
98-99 \% \text { in the diagnosis of IBD }\end{array}$ & $\begin{array}{l}\text { Can be used as a method of } \\
\text { monitoring treatment response }\end{array}$ \\
\hline Endoscopy & $\begin{array}{l}\text { In acute setting, flexible } \\
\text { sigmoidoscopy } \\
\text { Ileocolonoscopy is recommended } \\
\text { in all patients to delineate disease } \\
\text { extent, severity of inflammation } \\
\text { and to exclude Crohn's disease; } \\
\text { also for surveillance }\end{array}$ & $\begin{array}{l}\text { Erythema, oedema, loss of vascular } \\
\text { pattern, blood and ulcers/erosions }\end{array}$ & $\begin{array}{l}\text { Mayo score and Ulcerative Colitis } \\
\text { Endoscopic Index of Severity } \\
\text { (UCEIS) score are used to assess } \\
\text { severity of ulcerative colitis } \\
\text { endoscopically }\end{array}$ \\
\hline Histology & $\begin{array}{l}\text { Recommend at least two biopsies } \\
\text { from each bowel segment for } \\
\text { histological assessment }\end{array}$ & $\begin{array}{l}\text { No histological features are } \\
\text { diagnostic of UC, but basal } \\
\text { plasmacytosis, crypt atrophy/ } \\
\text { distortion and villous surface } \\
\text { irregularity are suggestive of UC }\end{array}$ & $\begin{array}{l}\text { The presence of granulomas is more } \\
\text { suggestive of Crohn's disease }\end{array}$ \\
\hline Imaging & Abdominal X-ray & $\begin{array}{l}\text { Thumbprinting, lead-piping, } \\
\text { oedema and toxic megacolon }\end{array}$ & \\
\hline Imaging & Cross sectional imaging: CT/MRI & $\begin{array}{l}\text { Bowel wall oedema and } \\
\text { inflammatory pseudopolyps }\end{array}$ & $\begin{array}{l}\text { Small bowel imaging can help } \\
\text { differentiate between UC and } \\
\text { Crohn's disease in challenging cases }\end{array}$ \\
\hline
\end{tabular}

$\mathrm{CT}=$ computed tomography; IBD = irritable bowel disease; MC\&S = microscopy, culture and sensitivity; MRI = magnetic resonance imaging; TPMT = thiopurine methyltransferase; $U C=$ ulcerative colitis.

therapeutic targets in IBD which were later updated in December 2020 in the SPIRIT consensus. ${ }^{6,7}$ In summary, this consensus agreed that UC treatment goals should address a composite of clinical and endoscopic outcomes (potentially with use of surrogate measures of inflammation, such as faecal calprotectin), in addition to the ultimate goals of addressing impact on a patient's life (health-related quality of life, disability and faecal incontinence), preventing disease extension, surgery, permanent stoma, and dysplasia or cancer.

\section{Determining severity of disease presentation}

Disease severity is measured by assessment of clinical and biochemical parameters, as showcased by the modified Truelove and Witts criteria (Table 2). ${ }^{4}$ Endoscopically, the Ulcerative Colitis Endoscopic Index of Severity (UCEIS) is the only validated scoring system to assess severity, however, the Mayo score is commonly used in clinical practice due to its simplicity in application. 4,8 $^{2}$

\section{Medical therapy}

5-aminosalicylic acid (5-ASA) drugs represent the standard therapy for patients with mild to moderate disease activity for induction and maintenance of UC. In patients with mild to moderate UC proctitis, 5-ASA suppositories are considered the first-line therapy, more so than oral 5-ASA monotherapy and rectal corticosteroids. ${ }^{4}$ In case of suboptimal response, addition of oral 5-ASA therapy should be the next step. ${ }^{4}$ If response remains incomplete, adding a corticosteroid suppository and/or optimising the oral 5-ASA dosing is recommended. ${ }^{4} \mathrm{UC}$ patients with left-sided disease or extensive colitis should be offered dual therapy with oral 5-ASAs and topical 
Table 2. Modified Truelove and Witts criteria

\begin{tabular}{llll} 
Parameter & Mild & Moderate & Severe \\
Bloody stool per day, $\mathrm{n}$ & $<4$ & $4-6$ & $>6$ \\
Pulse, beats per minute & $<90$ & $\leq 90$ & $>90$ \\
Temperature,$^{\circ} \mathrm{C}$ & $<37.5$ & $37.5-37.8$ & $>37.8$ \\
Haemoglobin, g/dL & $>11.5$ & $11.5-10.5$ & $<10.5$ \\
ESR, mm/h (or CRP, mg/L) & $<20$ & $20-30$ & $>30$ \\
& (normal) & $(<30)$ & $(>30)$ \\
\hline
\end{tabular}

$\mathrm{CRP}=\mathrm{C}$-reactive protein; $\mathrm{ESR}=$ erythrocyte sedimentation rate.

5-ASA. ${ }^{4}$ Oral 5-ASA doses of 2-3 g daily are sufficient in the induction of remission of most UC patients with mild to moderate activity. ${ }^{4}$ However, higher dosage ( $\geq 4 \mathrm{~g}$ daily) has been proven more effective in achieving clinical remission. ${ }^{4}$ 5-ASAs are well tolerated; renal impairment is a rare and an unpredictable adverse event, hence renal function should be checked regularly after 5-ASA initiation. ${ }^{4}$

Prednisolone should be restricted to patients with moderate to severe UC of any disease extent or those who are unresponsive to standard therapy. Alternatively, for cases of mild to moderate UC, a multi-matrix formulation of budesonide (budesonide multimatrix system (MMX)) was shown superior to placebo at a daily dose of $9 \mathrm{mg}$ over an 8-week course. ${ }^{4}$ Systemic adverse events of budesonide are considered fewer compared with conventional corticosteroids. Budesonide is not thought to induce adrenal suppression nor a significant reduction in bone mineral density. ${ }^{4}$

Thiopurines, such as azathioprine and mercaptopurine, have been used in maintenance of steroid-free remission. Thiopurines are associated with adverse events, with an estimated risk of $26 \%$ in a Spanish database study, including nausea (8\%), hepatotoxicity $(4 \%)$, myelotoxicity $(4 \%)$, pancreatitis $(4 \%)$, non-melanoma skin cancers and lymphomas. Assessment of thiopurine methyltransferase (TPMT) status is recommended prior to thiopurine initiation, while measurements of thiopurine metabolites may be used in monitoring. ${ }^{4}$

Biologics have progressively changed the therapeutic landscape of UC (Fig 1). Choice of biologic agent depends on many factors, including route of administration, side effects, potential immunogenicity, speed of response to induction therapy, overall costs and availability of infusion facilities. Anti-tumour necrosis factor (TNF) drugs include intravenous infliximab originator and biosimilars, subcutaneous adalimumab originator and biosimilars, and subcutaneous golimumab. Primary response rates of infliximab in UC patients who failed standard therapy varied from $67 \%$ to $78 \%$ in real-world data. ${ }^{9}$ Anti-TNF agents are preferred in patients with extra-intestinal manifestations of IBD, such as type 1 IBD-associated arthropathy, ankylosing spondylitis and pyoderma gangrenosum. ${ }^{10}$ Formation of neutralising anti-drug antibodies is recognised as a reason for loss of response to antiTNF drugs over time, which may be prevented by addition of an immunomodulator drug. Trials addressing combination therapy in UC have mostly studied the positive impact of combined infliximab and thiopurines; therefore, it is recommend that combination therapy with a thiopurine when infliximab is used as induction therapy for moderate to severe UC. ${ }^{4}$ Serum drug and anti-drug antibody levels should be measured in patients considered to have lost response to an anti-TNF drug in order to guide therapeutic decision making (dose escalation or switch to a different antiTNF or biologic class). The use of anti-TNF drugs may increase two-fold the pooled infectious risks (including tuberculosis, herpes zoster, cytomegalovirus among others (risk ratio (RR) 2.05; 95\% CI 1.1-3.85)), thus justifying a pre-biologics screen for tuberculosis, HIV, herpes zoster and hepatitis B and $C^{11}$

Vedolizumab inhibits $\alpha 4 \beta 7$ integrin, thus decreasing leukocyte migration from the circulation into the bowel wall. Such a gutselective pathway may explain the relative long-term safety of the drug. ${ }^{12}$ In the GEMINI 1 study, response rates at week 6 were $47.1 \%$ in the vedolizumab group and $25.5 \%$ in the placebo group

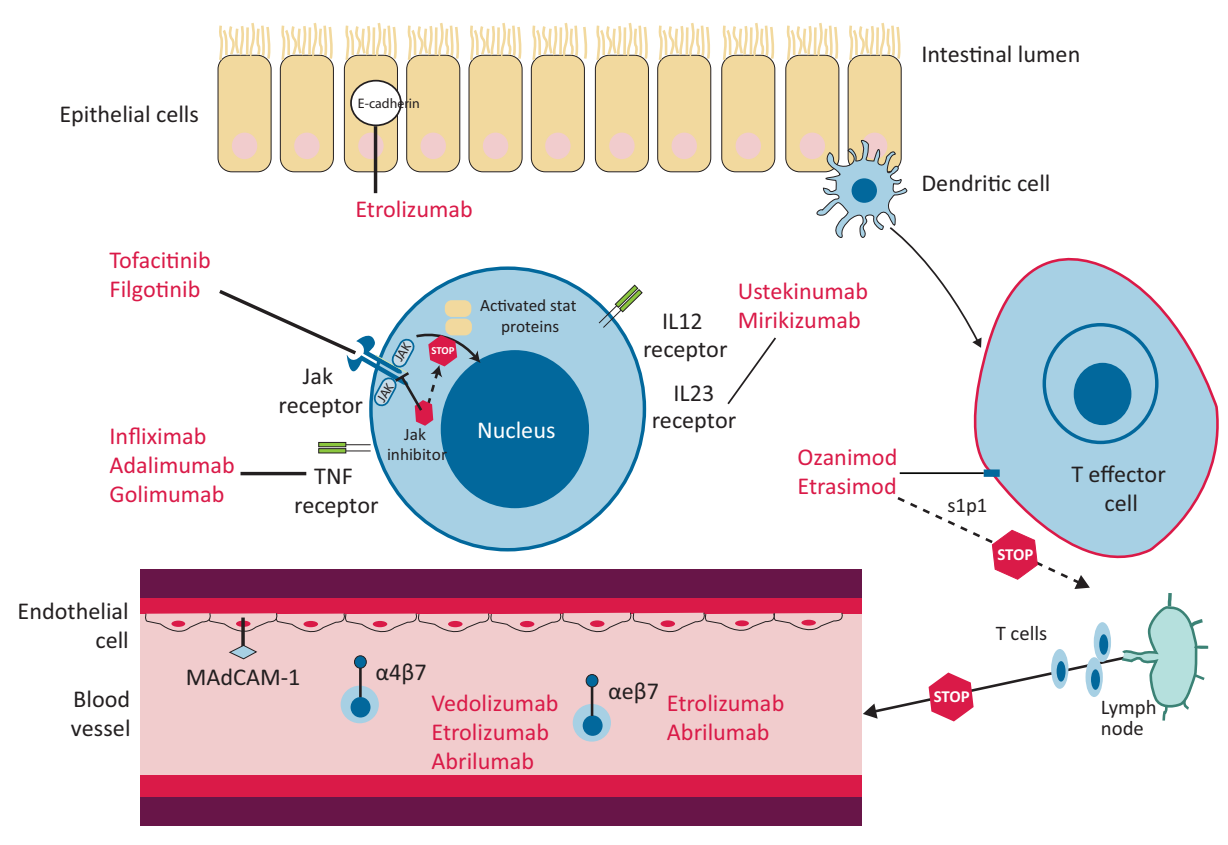

Fig 1. Mechanisms of action for biologics and small molecules used in ulcerative colitis. $\alpha 4 \beta 7=$ alpha- 4 beta-7 integrin; $\alpha$ e $\beta 7$ = alpha-e beta-7 integrin; IL = interleukin; Jak = Janus kinase; MAdCAM-1 = mucosal vascular addressing cell adhesion molecule-1; s1p1 = sphingosine1-phosphate receptor; Stat $=$ signal transducer and activator of transcription; TNF = tumour necrosis factor. 
$(p<0.001)$. For those who went into the maintenance trial, $41.8 \%$ who received 8 -weekly vedolizumab and $44.8 \%$ who received vedolizumab every 4 weeks were in clinical remission compared with $15.9 \%$ in the placebo group at week $52(p<0.001) .{ }^{13} \mathrm{~A}$ head-to-head double-blind randomised controlled trial, the first to compare biologics in IBD between intravenous vedolizumab and subcutaneous adalimumab, showed higher rates of clinical remission and mucosal healing in the vedolizumab group at 52 weeks. $^{14}$

Ustekinumab inhibits the $\mathrm{p} 40$ subunit of interleukins-12 and 23 ; in the UNIFI study, it was shown that $15.5 \%$ receiving ustekinumab achieved clinical remission at 8 weeks $(p<0.01)$ compared with $5.3 \%$ receiving placebo. Of those who responded to induction, by week $44,38.4 \%$ of those receiving ustekinumab every 12 weeks and $43.8 \%$ of those receiving ustekinumab every 8 weeks achieved clinical remission compared with $24 \%$ in the placebo group $\left(p=0.002\right.$ and $p<0.001$, respectively). ${ }^{15}$ Clinical trial data suggest low rates of adverse events. ${ }^{16}$

Tofacitinib is an oral Janus kinase (JAK) inhibitor, which showed improvement in composite clinical/endoscopic outcomes in $16.6-18.5 \%$ of patients during the induction trials, compared with $3.6-8.2 \%$ of patients receiving placebo. At 1 year, remission was significantly higher in the treatment arms $(34.3 \%$ in the $5 \mathrm{mg}$ twice daily (BD) group and $40.6 \%$ in the $10 \mathrm{mg}$ BD group), compared with $11.1 \%$ in the placebo group. ${ }^{17}$ Adverse events include a higher risk of herpes zoster infection, justifying adequate zoster vaccination, and increased risk of venous thromboembolism (VTE) reported on the $10 \mathrm{mg} \mathrm{BD}$ dosing. ${ }^{18}$ Higher doses should be avoided in patients considered at high risk of VTE.

\section{Follow-up and monitoring}

Patient understanding and engagement in their care is crucial. Clinical parameters should be re-assessed every 3 months during the active phase. Once symptoms have resolved, clinical reviews should be performed every 6-12 months. Colonoscopies should be performed every $1-5$ years to investigate suspected flares and to ensure surveillance of colorectal dysplasia, preferably with dye-spray chromoendoscopy. ${ }^{8}$

\section{Acute severe ulcerative colitis and surgical therapy including pouch implications}

In the case of acute severe ulcerative colitis (according to the Truelove and Witts), the mainstay of treatment is intravenous steroids. For those not responding to intravenous steroids, a decision on day 3 is crucial using one of the various indices as a guide. ${ }^{4}$ In this situation, either ciclosporin or infliximab maybe used as rescue therapy, with studies showing that there is no difference in efficacy. ${ }^{19}$ Importantly, at the stage where rescue therapy is considered, it is imperative that surgical options are also explored.

The timing of surgical intervention in a patient with $U C$ is multifactorial and needs to take into account disease severity and quality of life. In terms of acute severe ulcerative colitis that has not responded to medical therapy, a colectomy can be a life-saving procedure. For these patients who are offered surgery, a subtotal colectomy is the operation of choice. Surgical options include a permanent ileostomy, or restorative options to include the ileoanal pouch or, in some very selected cases, an ileorectal anastomosis. Importantly, when considering surgical options for patients with ulcerative colitis it is important to involve the multidisciplinary team to include surgeons, stoma nurses, pouch nurses and dietitians to counsel patients about expectations from the surgical options.

\section{The future}

There are a number of therapeutic targets being explored in the treatment of ulcerative colitis in various clinical phases to include sphingosine-1-phosphate receptor modulators (such as ozanimod and etrasimod), JAK inhibitors (such as upadacitinib), anti-leukocyte integrins (such as etrolizumab and abrilumab), monoclonal antibodies (such as mirikizumab) and faecal microbiota transplantation. ${ }^{20}$ These potentially will offer new options for the medical treatment of ulcerative colitis, but currently remain at the clinical trial phase.

Head-to-head trials are likely to enable us to position biologics correctly. As we gain a better understanding of the biological mechanisms that drive UC, it may become possible to find the right drug for the right person at the right time, while also ensuring that the broader goals of the patient (impact on quality of life, psychological and dietary support) are addressed.

\section{References}

1 Pasvol T], Horsfall L, Bloom S et al. Incidence and prevalence of inflammatory bowel disease in UK primary care: a populationbased cohort study. BMJ Open 2020;10:e036584.

2 Jones GR, Lyons M, Plevris $\mathrm{N}$ et al. IBD prevalence in Lothian, Scotland, derived by capture-recapture methodology. Gut 2019;68:1953-60.

3 Kobayashi T, Siegmund B, Le Berre C et al. Ulcerative colitis. Nat Rev Dis Prim 2020;6:74.

4 Lamb CA, Kennedy NA, Raine T et al. British Society of Gastroenterology consensus quidelines on the management of inflammatory bowel disease in adults. Gut 2019;68:s1-106.

5 Shah SC, Itzkowitz SH. Reappraising risk factors for inflammatory bowel disease-associated neoplasia: implications for colonoscopic surveillance in IBD. J Crohn's Colitis 2020;14:1172-7.

6 Peyrin-Biroulet L, Sandborn W, Sands BE et al. Selecting Therapeutic Targets in Inflammatory Bowel Disease (STRIDE): determining therapeutic goals for treat-to-target. Am. J Gastroenterol 2015;110:1324-38.

7 Le Berre C, Peyrin-Biroulet L, SPIRIT-IOIBD study group. Selecting Endpoints for Disease-Modification Trials in Inflammatory Bowel Disease: the SPIRIT consensus from the IOIBD. Gastroenterology 2021:S0016-5085(21)00016-0 [Epub ahead of print].

8 Travis SPL, Schnell D, Krzeski P et al. Reliability and initial validation of the ulcerative colitis endoscopic index of severity. Gastroenterology 2013:145:987-95.

9 Oussalah A, Evesque L, Laharie D et al. A Multicenter experience with infliximab for ulcerative colitis: outcomes and predictors of response, optimization, colectomy, and hospitalization. Am J Gastroenterol 2010;105:2617-25

10 Arvikar SL, Fisher MC. Inflammatory bowel disease associated arthropathy. Curr Rev Musculoskelet Med 2011;4:123-31.

11 Ford AC, Peyrin-Biroulet L. Opportunistic infections with antitumor necrosis factor- $\alpha$ therapy in inflammatory bowel disease: meta-analysis of randomized controlled trials. Am J Gastroenterol 2013:108:1268-76.

12 Loftus EV, Feagan BG, Panaccione R et al. Long-term safety of vedolizumab for inflammatory bowel disease. Aliment Pharmacol Ther 2020:52:1353-65. 
13 Feagan BG, Rutgeerts P, Sands BE et al. Vedolizumab as induction and maintenance therapy for ulcerative colitis. N Engl J Med 2013;369:699-710.

14 Sands BE, Peyrin-Biroulet L, Loftus EV et al. Vedolizumab versus adalimumab for moderate-to-severe ulcerative colitis. N Engl ] Med 2019;381:1215-26.

15 Sands BE, Sandborn WJ, Panaccione R et al. Ustekinumab as induction and maintenance therapy for ulcerative colitis. N Engl ] Med 2019;381:1201-14.

16 Sandborn W], Sands BE, Panaccione R et al. OP37 Efficacy and safety of ustekinumab as maintenance therapy in ulcerative colitis: Week 44 results from UNIFI. J Crohn's Colitis 2019;13(Suppl_1):S025-6.

17 Sandborn W], Su C, Sands BE et al. Tofacitinib as induction and maintenance therapy for ulcerative colitis. N Engl J Med 2017;376:1723-36.
18 Sandborn W], Panés ], Sands BE et al. Venous thromboembolic events in the tofacitinib ulcerative colitis clinical development programme. Aliment Pharmacol Ther 2019;50:1068.

19 Williams JG, Alam MF, Alrubaiy L et al. Infliximab versus ciclosporin for steroid-resistant acute severe ulcerative colitis (CONSTRUCT): a mixed methods, open-label, pragmatic randomised trial. Lancet Gastroenterol Hepatol 2016;1:15-24.

20 Danese $\mathrm{S}$. New drugs in the ulcerative colitis pipeline: prometheus unbound. Gastroenterology 2020;158:467-70.

Address for correspondence: Dr Jonathan Segal, Hillingdon Hospital, Pield Heath Road, Uxbridge UB8 3NN, UK.

Email: jonathansegal1@nhs.net

Twitter: @jonathansegal85 